\title{
A basic study on high volume flexible manufacturing system for agile manufacturing
}

Susumu Fujii, Hiroshi Morita

Dept. of Computer and Systems Engineering, Kobe University

Nada, Kobe 657, JAPAN,

Tel:+81-78-803-1203 Fax:+81-78-803-1218

E-mail:fujii@seg.kobe-u.ac.jp, morita@seg.kobe-u.ac.jp

Yasuto Tatsuta

Product and Production Engineering Administration Office,

Mazda Motor Corporation

Fuchu, Aki, Hiroshima 730-91, JAPAN

Tel:+81-82-287-4367 Fax:+81-82-287-5163

E-mail:ytatsuta@mazda.co.jp

Yoshiharu Takata

Development and Design Division, Yamazaki Mazak Corporation Oguchi, Aichi 480-01, JAPAN

Tel:+81-587-95-7796 Fax:+81-587-95-5812

E-mail:mazak@po.iijnet.or.jp

\begin{abstract}
We propose a new manufacturing system for agile manufacturing. It is necessary for an agile manufacturing system to produce a large amount and many kinds of products with high reliability. We propose a new configuration of manufacturing system, which attains the high flexibility for the high volume production. The system, named High Volume Flexible Manufacturing System (HV-FMS), consists of machining centers arranged in a serial and parallel manner. It is also expected to ensure high productivity for the case of machine troubles. Simulation studies are performed to demonstrate the feasibility and the effectiveness of the proposed system.
\end{abstract}

\section{Keywords}

Agile manufacturing, High volume flexible manufacturing system, Parallelserial configuration, Flow type production 


\section{INTRODUCTION}

In recent manufacturing systems, it is necessary to process many kinds of products to meet the increasing and varying demand of customers. As a result, the life cycle of products is becoming shorter and shorter and the agility in manufacturing is required to respond quickly to the changes not only in the variety but also in the quantity of products without losing the high quality (Kidd 1993, Goldman, et al 1995).

The flexible manufacturing systems (FMS) have been introduced to improve the productivity in manufacturing many kinds of products with a small or medium volume, aiming at medium production capacity in a whole (Ito \& Iwata 1984, Archetti, et al 1989, Raouf \& Ben Daya 1995). Because of the frequent changes in the kinds and volume of workpieces even in the mass production such as in automotive industries, it is becoming necessary to develop manufacturing systems not only the flexibility but also a large production capacity, which have been provided by dedicated transfer machines (TM) and flexible transfer lines (FTL).

In this study,we propose a new manufacturing system, named a high volume flexible manufacturing system (HV-FMS), for agile manufacturing which attains the high flexibility for the high volume production satisfying the above requirements. The system consists of machining cells arranged in a serial and parallel manner, where parallelly arranged machining cells with the same tooling set up form a group to process a certain portion of machining processes. That particular parallel-serial arrangement of machining cells is expected to provide both the "high flexibility" of the conventional FMS in job shop, and the "high productivity" of the transfer machine or the flexible transfer line in flow shop. At the same time, it is expected to ensure high productivity even in the case of machine troubles.

In section 2, we discuss the proposed new manufacturing system, HV-FMS, in detail after a brief description of the development of manufacturing systems. To study the feasibility of HV-FMS from a viewpoint of design, we perform a basic research on the manufacturing system which manufactures cylinder heads. Simulation is extensively used in this study because of its effectiveness in evaluating various manufacturing systems(Carrie 1988). The simulation results of the performance of HV-FMS is shown in section 3. Further research directions and concluding discussion are given in section 4 .

\section{HIGH VOLUME FLEXIBLE MANUFACTURING SYSTEM}

\subsection{A new manufacturing system for agile manufacturing}

We discuss in this section the historical change of manufacturing system and the goal of our proposed manufacturing system. As shown in Fig. 1, there are two major directions that the manufacturing systems have been developed 


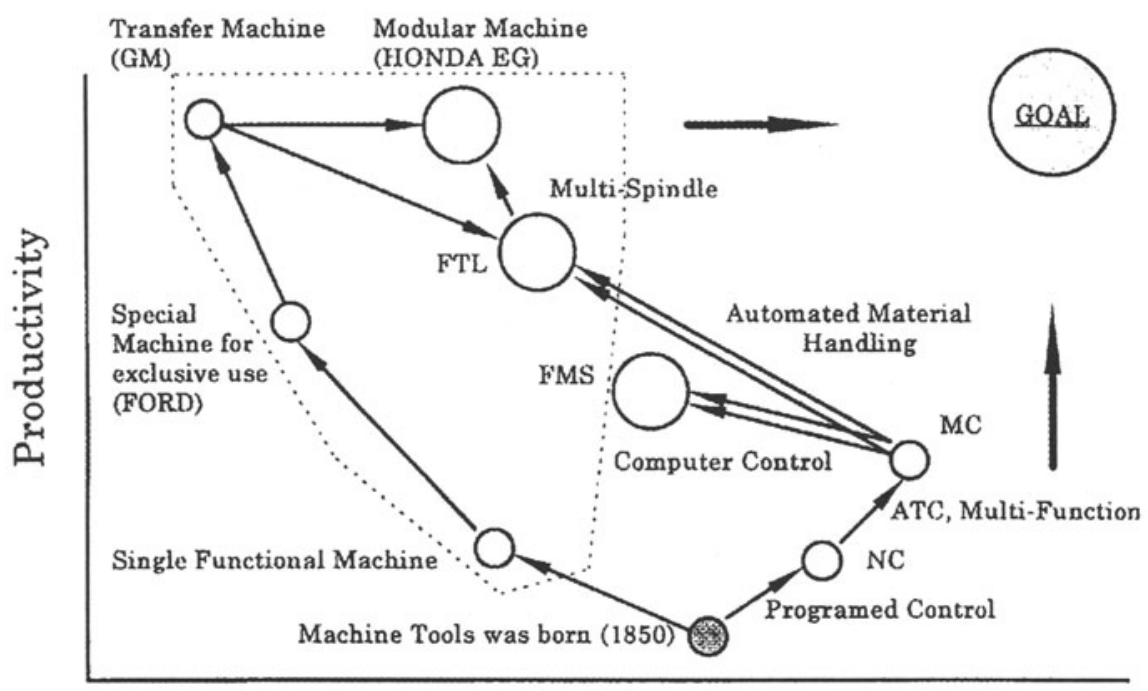

Flexibility

Figure 1 Development of manufacturing system

along with the automation: One is to improve the productive efficiency, and the other is to improve the flexibility for products.

To improve the productivity, single functional machines with high machining speed and a line production system such as a transfer machine(TM) are intensively developed for a mass production. Since these systems do not have high flexibility for the change of products and are appropriate to the low-diversity production, the flexible transfer line(FTL) was introduced as a system to provide some flexibility with high productivity.

To improve the flexibility, it is desired to produce many kinds of and small amount of products to respond the customers request and demand quickly. This led the introduction of multi-functional machining center. Since it is for job-shop type production, the productivity is not so high. Therefore the computer controlled flexible manufacturing system and flexible manufacturing cell are intensively developed to improve their productivity keeping the flexibility(Ito and Iwata (1984)).

For agile manufacturing, it is becoming more important to pursue both high productivity and high flexibility. To attain such ultimate goal at the right upper corner in Fig. 1, a new manufacturing system is so designed to possess the high productivity of the line production system and the high flexibility of the multi-functional production system at the same time. 


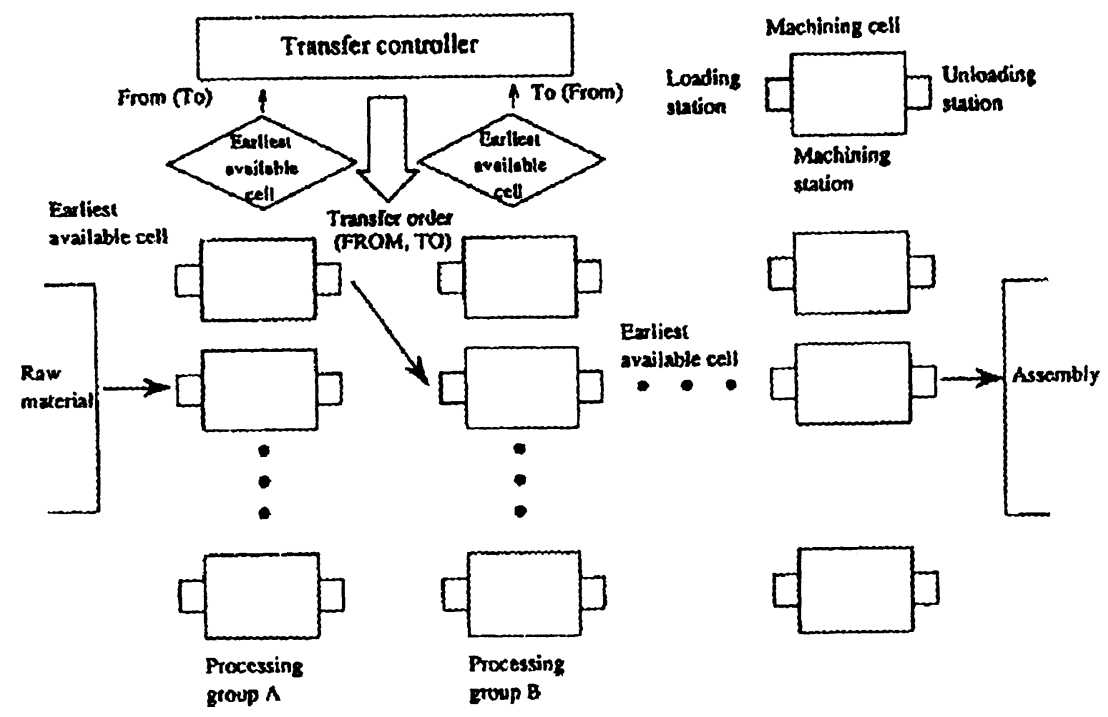

Figure 2 The workpiece flow in high volume flexible manufacturing system

\subsection{Essential factors of HV-FMS}

The essential factors of a high volume flexible manufacturing system (HVFMS) proposed in this study are "flexibility" and "productivity". Flexibility requires the highly mixed production of different type of workpieces, expandability and reducibility in amount adapting the variable demands, and adaptability to the progress in technology. Productivity requires the quick response for shortening the production lead time and the production preparation time, and stability and reliability of system.

The HV-FMS is designed for high volume parts production using a particular parallel-serial arrangement of machining cells. Fig. 2 shows a typical workpiece flow in HV-FMS. The manufacturing system of HV-FMS consists of "cells" as the basic units, each of which consists of loading station, machining station and unloading station. Each cell forms an independent subsystem and the total system is an integration of these cells. The machining process of one product is divided into several processing groups. The processing groups are arranged in a series and all products are processed according to the order of processing groups. Machining processes in one group can be achieved by any machining cell in the group, where the machining cells have flexibility for processing many kinds of workpieces by providing sufficiently many tools in the tool magazine or changing tools. 
The raw material stored in the warehouse is loaded into the machining system, where the production schedule should be dynamically determined based on the operating conditions of machining cells varying time to time. The workpieces are transported to a machining cell by automated guided vehicles (AGVs). The transportation controller should select the machining cell by which the workpiece is processed and the AGV by which the workpiece is transported. Dispatching rules such as the earliest available machining cell and the earliest available AGV, are used for the control in this study.

Multi-functional machining cells are utilized in HV-FMS, where the rate of machine failure may become larger than the single-functional machine system. The parallel arrangement of the machining cells with the same specification ,however, will enable to continue the processing by alternative machining cells when machine trouble occurs. Therefore, it is considered that the HV-FMS is robust for the machine failure and maintain the high productivity even under larger failure rate of machining cell.

\section{SIMULATION STUDIES OF HV-FMS}

\subsection{Purpose of simulation study}

The feasibility and effectiveness of the proposed HV-FMS. It is necessary to test and evaluate the performance of various system configurations by some means and determine the desirable configration. In the development of FMS, simulation has been widely and effectively used as reported in many literatures, e.g., (Carrie 1988). We study an HV-FMS which hypothetically manufactures the cylinder heads of automobile engines. We consider the evaluating criteria of the HV-FMS as utilization of processing groups and AGVs, production lead time of each kind of workpiece and total amount of production.

We have executed the following three experiments.

1. Clarify the relation between the number of machining cells and product mix of workpiece, and show the robustness for the change of product mix of workpieces.

2. Find the sufficient number of AGV.

3. Verify the robustness for machine failure.

\subsection{Simulation parameters}

The design parameters are the number of machining cells in each processing group and the number of AGVs. The environmental parameters are the product mix of workpieces and the distribution of machine failure. In this simulation model, we assume to process three kinds of workpieces (I, II and III) and the machining processes are divided into 5 processing groups (A, B, C, D 
Table 1 The processing times and the number of machining cells in each processing group

\begin{tabular}{rrrrrr}
\hline $\begin{array}{r}\text { Processing } \\
\text { group }\end{array}$ & $\begin{array}{r}\mathrm{A} \\
(\mathrm{sec})\end{array}$ & $\begin{array}{r}\mathrm{B} \\
(\mathrm{sec})\end{array}$ & $\begin{array}{r}\mathrm{C} \\
(\mathrm{sec})\end{array}$ & $\begin{array}{r}\mathrm{D} \\
(\mathrm{sec})\end{array}$ & $\begin{array}{r}\mathrm{E} \\
(\mathrm{sec})\end{array}$ \\
\hline Work I & 472 & 389 & 504 & 78 & 240 \\
Work II & 472 & 445 & 647 & 102 & 353 \\
Work III & 853 & 502 & 673 & 126 & 466 \\
\hline$\sum w_{j} p_{i j}$ & 535.5 & 426.5 & 579.8 & 94.0 & 315.3 \\
$N_{i}$ & 10.9 & 8.7 & 11.8 & 1.9 & 6.4 \\
$\hat{N}_{i}$ & 11 & 9 & 12 & 2 & 7 \\
\hline
\end{tabular}

and E). The capacity of loading and unloading stations is assumed to be one. The AGV can transport one workpiece at a time and is assumed to be failure free for simplicity. The time for transportation by AGV is assumed to be normally distributed with the mean of 54 seconds and the standard deviation of 12 seconds including the loading time, unloading time and transportation time. And no conflict of AGVs is assumed in this study.

The number of machining cells in each processing group is basically determined by the following relations.

$$
\begin{gathered}
N_{i}=\left(\sum_{j=I}^{I I I} w_{j} p_{i j}\right) / c_{i}, \quad i=A, B, C, D, E \\
w_{j} \geq 0, w_{I}+w_{I I}+w_{I I I}=1
\end{gathered}
$$

where $w_{j}$ is the product mix of work $j, p_{i j}$ is the processing time of work $j$ in the processing group $i$ and $c_{i}$ is the cycle time of processing group $i$. The cycle time is obtained by assuming that the total amount of products per month is 30,000 , the operation time is 480 hours and the expected system utilization is set to $85 \%$. Then we have

$$
c_{i}=480 / 30000 \times 0.85=0.0136 \text { (hours) }=49 \text { (seconds) }
$$

The practical data of processing times used in the simulation study are shown in Table 1, where the number of machining cells are estimated by using the product mix of $w_{I}=50.0 \%, w_{I I}=33.3 \%$ and $w_{I I I}=16.7 \%$. The fundamental number of machining cells $\hat{N}_{i}$ is given by rounding $N_{i}$.

As the dispatching rule for assigning machining cell and AGV, we use the earliest available rule. 


\subsection{Results of simulating experiments}

\subsubsection{The number of MCs vs product mix}

The first study is how the productivity is affected by the change of number of machining cells and product mix. The number of AGVs are fixed to three in each transportation area and no machine failure is assumed. We have examined four arrangements of machining cells and three types of product mix as given below. Note that MC I, II and III are obtained by eq.(1) with PM I, II and III, respectively. In MC IV, a machining cell in group E is reduced from $\mathrm{MC}$ I.

- four arrangements of machining cells of five processing groups

- MC I $(11,9,12,2,7)$

- MC II $(11,9,13,2,6)$

- MC III $(10,9,13,2,7)$

$-\operatorname{MC} I V(11,9,12,2,6)$

- three types of product mix of three kinds of workpieces

- PM I $(50.0 \%, 33.3 \%, 16.7 \%)$

- PM II $(33.3 \%, 33.3 \%, 33.3 \%)$

- PM III $(0.0 \%, 100.0 \%, 0.0 \%)$

Figs. 3 show the total utilization of machining cells and AGVs, respectively. Every combinations of $\mathrm{MC}$ and PM give the higher utilization more than $85 \%$. Especially, MC III gives comparatively low utilization, which is induced from that the number of machining cells in first processing group A is smaller than the other MCs. Then the number of processed workpieces decreases, although the total number of machining cells are the same. PM III gives the highest utilization for any MCs, since PM III is a single kind production. In general, every MCs except for MC III are robust against the change of product mix. The utilization for MC IV is slightly less than that of MC I.

\subsubsection{The number of $A G V s$}

The second study is how the productivity is affected by the change of number of AGVs. The number of machining cells and product mix are fixed to MC I and PM I. No machine failure is also assumed here. Figs. 4 and 5 show the utilization of AGVs and machining cells and the production lead time for each kind of workpiece, respectively.

The utilization of AGVs is in inverse proportion to the number of AGVs and saturates to $92 \%$ when AGVs are less than two. The utilization of machining 


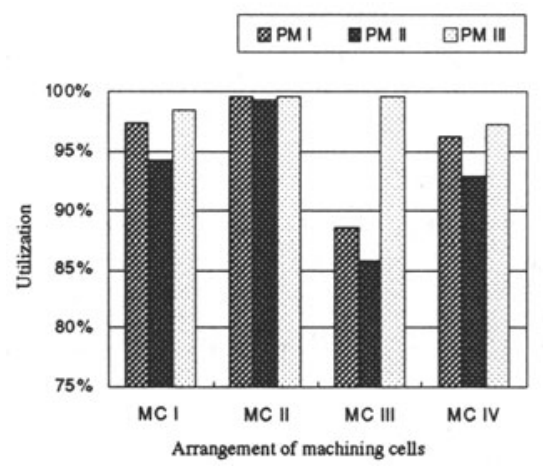

(a)machining cells

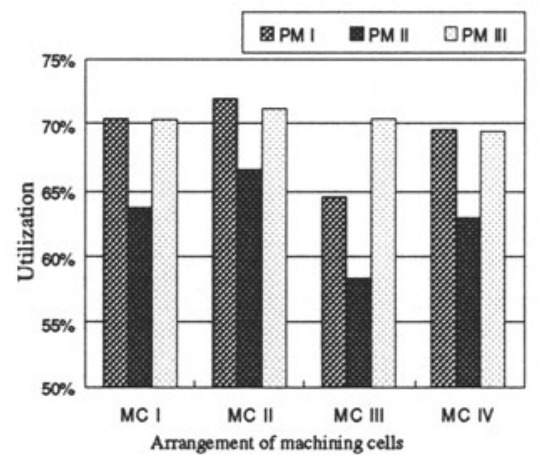

(b)AGVs

Figure 3 Utilization of machining cells and AGVs

cells also saturates to $97 \%$ when AGVs are more than three. Moreover, the production lead time for each work does not decrease for more than 3 AGVs. Therefore, three AGVs are sufficient in this model to maintain the highest productivity of this system. If the failure of machines and AGVs are taken into account, the utilization will decrease and the curves in Fig. 4 should shift to right. Then the number of AGVs for more efficient operation will increase.

\subsubsection{Machine failure}

The third study is how the productivity is affected by the machine failure. The number of machining cells and product mix are fixed to MC I and PM I. The failure rate of each machining cell is estimated from practical data of currently operating FMS. The time between failure (TBF) is exponentially 


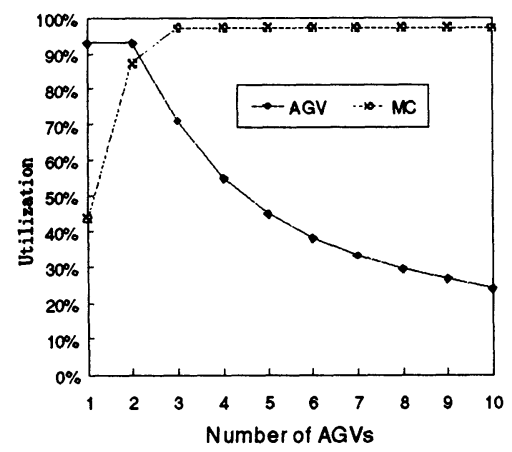

Figure 4 Utilization of AGVs and machining cells

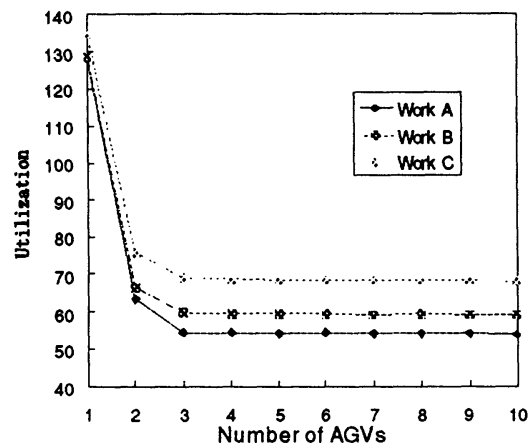

Figure 5 Production lead time

distributed with the mean of 430 hours and the time to repair (TTR) is lognormally distributed with the mean of 3.1 hours and the standard deviation of 3.3 hours. We call this failure type as Type I. Moreover, we consider two more failure types as follows. Type II is more frequently failed than Type I and moreover Type III takes longer time to repair than Type II.

$$
\begin{array}{ll}
\text { Type I } & \mathrm{TBF}=\operatorname{Exp}(430), \mathrm{TTR}=\log \mathrm{N}\left(3.1,3.3^{2}\right) \\
\text { Type II } & \mathrm{TBF}=\operatorname{Exp}(250), \mathrm{TTR}=\log \mathrm{N}\left(3.1,3.3^{2}\right) \\
\text { Type III } & \mathrm{TBF}=\operatorname{Exp}(250), \mathrm{TTR}=\log \mathrm{N}\left(7.0,22.2^{2}\right)
\end{array}
$$

Fig. 6 shows the utilization of AGVs and machining cells. When the time to repair is short as Type I and II, the reduction in utilizations of AGVs and 


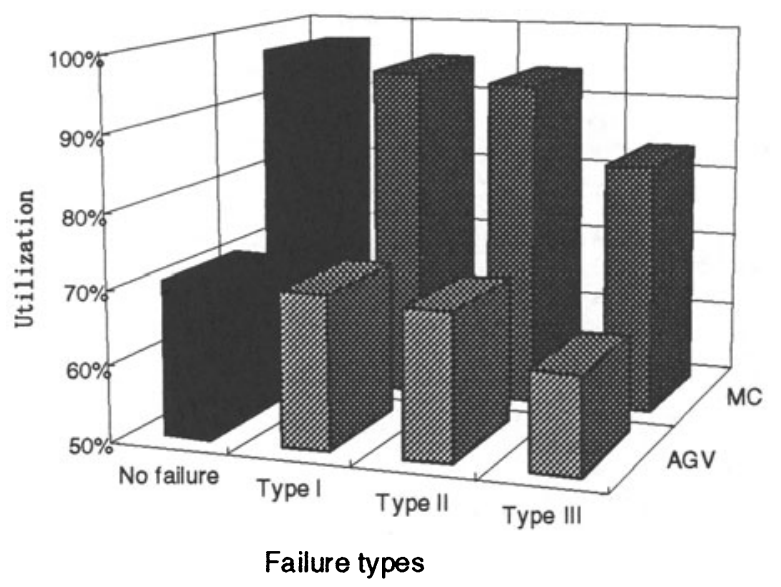

Figure 6 Utilization of AGVs and machining cells

machining cells is not serious, that is only 3 to $4 \%$. On the other hand, when the time to repair is long as Type III, there is comparatively large reduction in utilization, although the utilization of machining cells is still kept at the level of about $85 \%$.

\section{CONCLUDING REMARKS AND FURTHER RESEARCH TOPICS}

We have proposed a new manufacturing system for agile manufacturing named as high volume flexible manufacturing system(HV-FMS), which has a parallelserial configuration. For a specific product mix with a target production volume, a appropriate number of machining cells in each processing group is estimated. Simulation studies shows that an appropriate configuration exists for different product mixes. The total number of machining cells does not vary much for the change in the product mix although the number of cells assigned to each processing group may differ corresponding to the product mix. This suggests that the proposed system has the flexibility to form the appropriate configuration by changing the assignment and/or layout of machining cells in accordance with the change in the product mix. Considering the production amount of any tested cases were more than the target volume, the productivity and flexibility of the proposed system can be concluded to be satisfactory.

The study also showed that there exists appropriate number of AGVs connecting processing groups, and that the system performance is affected by the 
machine failure, but the effect of the time to repair is more significant than that of the time between failure.

To materialize proposed HV-FMS, many problems are left to be studied in future, some of which are listed in the following.

1. The pallet change between the processing group was assumed to be made at machining cells but is necessary to develop a practical and feasible method.

2. Practical method for dynamic assignment of machining cells is to be pursued for the improvement of the system performance.

3. Extensive studies on the system operation including selection rules of machining cells and AGVs are essential for efficient system operation.

4. The study from the economic view point of HV-FMS in comparison with the other manufacturing systems is essential for the feasibility study to implement the system in the factory.

\section{REFERENCES}

Archetti, F., Lucertini, M. and Serafini, P., Eds. (1989), Operations Research Models in Flexible Manfacturing Systems, CISM No.306, Springer-Verlag, New York, N.Y.

Carrie, A. (1988), Simulation of Manufacturing Systems, John Wiley, New York, N.Y.

Goldman, S.L., et al. (1995), Agile Competitors and Virtual Organizations, Strategies for Enriching the Customer, Van Nostrand Reinhold, New York, N.Y.

Ito, Y. and Iwata, K. (1984), Flexible Manufacturing System, Nikkan-KogyoShinbun, Tokyo. (in Japanese)

Kidd, P.T. (1995), Agile Manufacturing, forging New Frontiers, AddisonWesley Publ., Reading, Mass.

Raouf, A. and Ben-Daya, M., Eds. (1995), Flexible Manufacturing Systems: Recent Developments, Manufacturing Research and Technology 23, Elsevier Science B.V., Amsterdam.

\section{BIOGRAPHY}

Susumu Fujii received B.E. and M.E. from Kyoto University, and Ph.D. from the University of Wisconsin, Madison, in 1965, 1967 and 1971, respectively. He joined Kobe University in 1970 and is Professor of Computer and Systems 
Engineering at Kobe University. His research interests include computer integration of manufacturing systems, production planning and scheduling, and manufacturing system simulation.

Hiroshi Morita received B. E. and M.E. from Osaka University and Dr. E. from Kyoto University, 1983, 1985 and 1992, respectively. He joined Kobe University in 1993 after teaching at Osaka Prefectural University and Osaka City University and is Associate Professor of Computer and Systems Engineering at Kobe University. His research interests are operations research, efficiency analysis and production scheduling.

Yasuto Tatsuta received B.E. and M.E. from Osaka University in 1970 and 1972, respectively. He joined Mazda Motor Corporation in 1972 and is General Manager of Product and Production Engineering Administration Office.

Yoshiharu Takata received B.E. and M.E. from Tottori University in 1983 and 1985, respectively. He joined Yamazaki Mazak Corporation in 1985 and is Assistant Leader of Machining Technology Research Center in Development and Design Division. 